\title{
PREDATORS AND LIFE HISTORIES SHAPE LESTES DAMSELFLY ASSEMBLAGES ALONG A FRESHWATER HABITAT GRADIENT
}

\author{
Robby Stoks ${ }^{1,2}$ And Mark A. McPeeK ${ }^{1,3}$ \\ ${ }^{1}$ Department of Biological Sciences, Dartmouth College, Hanover, New Hampshire 03755 USA \\ ${ }^{2}$ Laboratory of Aquatic Ecology, University of Leuven, Ch. De Bériotstraat 32, B-3000 Leuven, Belgium
}

\begin{abstract}
Survey data from New England showed that assemblages of Lestes damselflies are organized along the entire gradient of pond permanence and predator presence. One assemblage occupies vernal ponds lacking large dragonfly predators and fish; four are largely confined to temporary ponds that typically contain dragonfly predators; one dominates fishless permanent ponds and lakes where dragonflies are the top predators; and one dominates permanent ponds and lakes where fish are the top predators. We determined the role of life history and predation in maintaining this striking pattern by conducting a series of transplant experiments in the field and a laboratory experiment manipulating presence and absence of local predators. Life history (1) shaped the ability of species to cope with drying regime, thereby excluding temporary-pond Lestes from vernal ponds and permanentwater Lestes from temporary ponds, and (2) generated size differences among species due to differences in the timing of hatching. This mediated the exclusion of temporary-pond Lestes from permanent water bodies through asymmetric intraguild predation by permanentwater Lestes. Dragonfly predation on permanent-water Lestes had an indirect positive effect on the survival of temporary-pond Lestes; however, this effect apparently is too small to allow coexistence of both Lestes groups. Predation by large dragonfly larvae excluded the Lestes species of vernal ponds from temporary ponds, and differential vulnerability to large dragonfly larvae and fish shaped the reciprocal dominance of $L$. eurinus and $L$. vigilax in fishless and fish-containing permanent water bodies, respectively. Taken together, these results show that life history constraints and predation both shape the distributions of Lestes species along the pond permanence gradient in New England. We discuss the importance of this freshwater habitat gradient in shaping local and regional species diversity.
\end{abstract}

Key words: coexistence; community assembly; damselfy; environmental gradient; hydroperiod; indirect effects; Lestes; life history; local vs. regional species richness; phenologic priority; predation.

\section{INTRODUCTION}

Species are not randomly distributed across the landscape. Predictable assemblages of species are usually found along major environmental gradients, and clear patterns of species turnover are associated with major ecological discontinuities along these gradients. An important and clearly defined gradient orders lentic freshwater habitats along an axis of hydroperiod, with small, temporary ponds that hold water for only a few weeks a year at one extreme, and large lakes that are essentially permanent bodies of water at the other extreme. Species from nearly every group of freshwater organisms sort along this environmental gradient, thus making it a critical axis along which aquatic communities are organized (reviewed in Wellborn et al. 1996). Understanding the processes that pattern species assemblages across this gradient requires that we understand the ecological interactions that restrict species to inhabiting only a subset of the environment gradient available to them. To reveal the fundamental role of

Manuscript received 5 July 2002; revised 14 October 2002; accepted 25 October 2002. Corresponding Editor: S. I. Dodson.

${ }^{3}$ Corresponding author.

E-mail: mark.mcpeek@dartmouth.edu these interactions, studies within only a single habitat type are not sufficient and a gradient approach is necessary (Wellborn et al. 1996).

Several ecological processes are known to vary in intensity along the freshwater habitat gradient, and these ecological processes have been shown to limit the distributions of some taxa along the gradient. Pond drying can be an important source of mortality for organisms at the more temporary end of the gradient (Smith 1983, Jeffries 1994, Skelly 1995); species inhabiting temporary ponds must be able to complete the obligate aquatic phases of their life cycle before pond drying to maintain populations at this end of the gradient (Wiggins et al. 1980). As water becomes more permanent, predation becomes a more important feature of the ecological milieu (Woodward 1983, Skelly 1995, 1996, Wellborn et al. 1996, Schneider 1997, Bilton et al. 2001). However, different top predators dominate different portions of the gradient, with invertebrate predators (particularly large dragonflies) dominating in the semipermanent range of the gradient and in permanent ponds and lakes that are inaccessible to fish colonization, and fish dominating on the permanent end of the gradient in ponds that have routes of colonization for them (Tonn and Magnuson 1982, Rahel 
1984, McPeek 1990a, Werner and McPeek 1994, Skelly 1996, Wilbur 1997, Williams 1997, Fauth 1999, Knapp et al. 2001). The intensity of competition may also change along the gradient as a result of changes in predator presence and composition (e.g., Werner and McPeek 1994, Werner and Anholt 1996). Emerging patterns so far show that community structure along the freshwater habitat is shaped primarily by pond drying and differences in predation, and that competition seems to be of minor importance in causing species exclusion along the gradient, although competition influences abundances of assemblage members where they can persist (reviewed in Wellborn et al. 1996).

The group that has been most intensively studied along the entire breadth of the gradient are the anurans, which inhabit ponds and lakes as larvae (e.g., Kats et al. 1988, Werner and McPeek 1994, Skelly 1995, 1996, Smith and Van Buskirk 1995, Richardson 2001). Pond drying and differences in predation regimes also influence the distributions of many invertebrate groups along the gradient as well (see reviews by Batzer and Wissinger 1996, Wellborn et al. 1996). Fish predation in lakes containing fish and invertebrate predation in fishless lakes clearly causes species in many taxa to segregate among permanent lakes based on predation regime both for limnetic and littoral species (e.g., Brooks and Dodson 1965, Bendell 1986, Arnott and Vanni 1993, McPeek 1990a, Wellborn 1995, 2002). At the more temporary end of the gradient, Wissinger et al. (1999b) have shown that a combination of habitat drying, intraguild predation, and salamander predation determined the habitat distribution of two species of limnephilid caddis flies going from vernal ponds to permanent fishless water bodies (see also Sprules 1972 and Dodson 1974 for similar examples in zooplankton). Studies focusing on the mechanisms shaping invertebrate community structure along the gradient from temporary ponds to permanent fish-containing lakes have typically focused on taxa that inhabit only part of the gradient, and/or have typically considered only a few, and typically only two, species (e.g., Brooks and Dodson 1965, McPeek 1990a, Arnott and Vanni 1993, Wellborn 1995, 2002, Wissinger et al. 1999b).

In this paper, we consider the ecological interactions that structure the assemblage of Lestes damselflies along this freshwater habitat gradient. Lestes are striking because members of this genus inhabit the entire breadth of the gradient from vernal ponds to large permanent lakes with fish. Moreover, different assemblages of Lestes are found at different ranges along the gradient. We present the results of laboratory and field experiments that identify key ecological interactions restricting species to different parts of the gradient, and thus generating patterns in the species assemblages along the gradient. Our results show that life history constraints, predation by fish and dragonflies, and intraguild predation among the Lestes themselves all act to restrict the distributions of Lestes species along the gradient. Our results also imply that a fourth community type should be added to Wellborn et al. (1996)'s model of community assembly along the gradient (see Discussion).

\section{NATURAL History}

Members of the genus Lestes can be found along the freshwater habitat gradient from vernal pools that dry yearly in early summer, temporary ponds that dry in late summer in some, but not every year, and permanent bodies of water. Only part of the distribution of Lestes species along the gradient can be explained by life history differences that lead to exclusion due to pond drying. All lestid damselflies are univoltine, and most overwinter as desiccation-resistant, diapausing eggs, followed by a short larval stage of $\sim 2-3$ months in spring and early summer (Gower and Kormondy 1963, Sawchyn and Gillott 1974, Jödicke 1997). During this larval period they pass through 10 instars (from F-9 to F-0, with F-0 being the final instar). In New England, species with this life history include $L$. congener Hagen, L. disjunctus Selys, L. dryas Kirby, L. forcipatus Rambur, L. rectangularis Say, and L. unguiculatus Hagen. This life history permits these Lestes species to potentially inhabit any position along the freshwater habitat gradient, except for the most vernal of ponds. Only L. dryas appears to have a short enough larval period to successfully emerge in vernal ponds that dry after only a few weeks in the spring and early summer (see Results and Wiggins et al. 1980).

The exception to the typical Lestes life history strategy is given by the direct developing eggs of L. eurinus Say, L. inaequalis Walsh, and L. vigilax Hagen (Lutz 1968, Paulson and Jenner 1971; M. A. McPeek, personal observation). For these species, eggs hatch soon after being laid in late June and July, and their aquatic larvae are present through May of the following year. Thus, their requirement to overwinter as aquatic larvae instead of diapausing eggs restricts them to permanent water bodies (they can be found in temporary water bodies that have not dried in several years; see Results). Life history constraints can, however, not explain (1) the near absence of L. dryas from temporary and permanent ponds and lakes, (2) the absence of temporarypond Lestes from permanent water bodies, and (3) the clear habitat separation between the permanent-water Lestes species (see Results). Water chemistry and competition can probably also not explain these three patterns. Abiotic conditions such as oxygen stress are thought to be less harsh with increasing permanence (Williams 1996), making it unlikely that they underlie patterns (1) and (2). Lestes, like other damselflies, are very resistant to low pH (Jödicke 1997), and their distribution is not related to $\mathrm{pH}$ (Bendell and McNicol 1987, McNicol et al. 1987). For example, in a survey of permanent lakes in Michigan, the only chemical factor that differed between fishless lakes with L. eurinus and fish-containing lakes with $L$. vigilax was a $\mathrm{pH}$ value 
that was, on average, slightly lower in fishless lakes, but with nearly completely overlapping ranges of $\mathrm{pH}$ (McPeek 1990a). Therefore, pattern (3) is also probably not caused by changes in water chemistry. Studies focusing on the potential role of competition in spatial segregation of coenagrionid damselfly larvae could not demonstrate any competitive exclusion (Pierce et al. 1985, McPeek 1990a, 1998). Therefore, the experiments described below were designed to test whether the major predators found at different ranges along the gradient, namely large dragonflies and fish, and intraguild predation by other Lestes species impose differential mortality on various Lestes species that can account for their distributions along the pond permanence gradient.

\section{Materials And Methods}

\section{Quantification of species occurrence along the gradient}

A number of previous studies have described the types of ponds inhabited by the larvae of various Lestes species across North America (Walker 1953, Johnson and Crowley 1980, Cannings and Cannings 1987, McPeek 1990a, Westfall and May 1996). To determine whether these distributional patterns hold in New England, we quantified the densities of Lestes damselfly larvae and their potential predators using a standardized protocol at 12 ponds and lakes across the gradient in the vicinity of Hanover, New Hampshire (see Appendix A).

\section{General methodology of the field experiments}

Field experiments with enclosures were conducted in natural water bodies to evaluate the contributions of predation in shaping the distribution of Lestes species along the gradient. We worked with the natural available distribution of larval instars at the time of the experiment for each damselfly species. Densities used were within the natural range encountered during the survey (none of the densities exceeded the maximum density encountered during one of the sweeps). Natural vegetation was added to each enclosure in densities mimicking the conditions at the study site.

At the start of each experiment one additional larval sample identical to the ones added to the enclosure was taken to determine the initial size and mass of the larvae. Head width was measured by digitizing an enlarged image of the head using OPTIMAS software (Optimas 1996). This initial sample of larvae and all larvae recovered from cages were dried for $>24 \mathrm{~h}$ at $64^{\circ} \mathrm{C}$, and their dry mass was determined to the nearest $0.01 \mathrm{mg}$ on an Ohaus Analytical Plus electrobalance (Ohaus, Florham Park, New Jersey, USA).

We used two types of enclosures. For relatively short experiments (a few days) or when very small instars were involved, we used 17-L white buckets filled with pond water for enclosures. Buckets were floated in styrofoam frames in a pond, and these frames were po- sitioned to float in $0.5 \mathrm{~m}$ deep water. The bottom of each bucket was covered with a 2-cm layer of detritus and aquatic vegetation, and the background prey population was added to reconstruct the environment of the natural site. Care was taken to exclude any damselfly and dragonfly larvae or other predators (e.g., beetle larvae and notonectids) when filling the enclosures. The tops of the enclosures were open, but no immigration of flying aquatic insects was observed.

For longer experiments ( $>3 \mathrm{wk}$ in duration), we used semipermeable enclosures in which small prey items could pass freely into and out of the cages. These enclosures were made of a cylindrical chicken-wire frame with a height of $120 \mathrm{~cm}$ and a diameter of $30 \mathrm{~cm}$ (dragonfly predation experiment) or $54 \mathrm{~cm}$ (fish predation experiment) (McPeek 1990a, 1998). This cylinder was covered with nylon mosquito netting $(0.6 \times 1.2 \mathrm{~mm}$ mesh size). The bottom of the enclosure was closed by a plastic dish. This plastic dish was filled to a depth of $2 \mathrm{~cm}$ with sediment, and aquatic vegetation in natural densities was added to enclosures after rinsing them vigorously to remove animals. These enclosures were placed in water at a depth of $80 \mathrm{~cm}$, with their open top extending $40 \mathrm{~cm}$ above the water level. No immigration of flying aquatic insects was detected. This type of enclosure was installed in a pond or lake one week before the start of the experiment to allow prey (e.g., copepods, cladocerans, amphipods, ephemeropterans, annelids) to colonize the cages. Coenagrionid damselfly larvae display natural mortality and growth rates under appropriate treatments in experiments using this same enclosure design (McPeek 1990a, 1998). With each experiment using these enclosures, we also deployed three enclosures that were handled identically to treatment enclosures, except that no damselfly larvae or predators were added. These served as controls to detect any potential immigration of Lestes larvae through the netting. We found no Lestes larvae in these control cages at the end of any experiment.

The potential role of predation was assessed by calculating mortality rate for each species (or species group) in each enclosure. A constant mortality rate $(m)$ was assumed (i.e., $N(t)=N(0) \times \exp (-m t)$ ), hence mortality rate was expressed as $m=-1.0 \times$ [ $\ln$ (number recovered) - $\ln$ (initial number added)]/ (duration of experiment in days). This gives a mortality rate that is comparable across experiments with different initial densities and durations. Differences in growth rate among treatments were assessed by comparing the dry masses of larvae recovered at the end of the experiment.

\section{Experiment 1: Anax predation in a temporary pond}

Our survey showed that L. dryas has a strong affinity for vernal ponds lacking large dragonfly predators (Appendix A). We established an experiment to test whether predation by large dragonfly predators excludes $L$. dryas larvae from temporary ponds where large drag- 
onfly larvae (e.g., Anax and Aeshna species) are common. Each of the experimental enclosures contained $L$. dryas and temporary-pond Lestes larvae. We studied their performance (survival, final size) under each of the two predator treatments: (1) no Anax predator added, and (2) one Anax predator added (Appendix B).

\section{Experiment 2: Anax and Lestes predation in a fishless permanent pond}

The field survey showed that L. eurinus is the only abundant Lestes present in permanent ponds and lakes with large dragonflies as top predators (Appendix A). The absence of temporary-pond Lestes from these permanent water bodies cannot be explained by hydroperiod or predation by the top predator (Anax is equally abundant in both habitat types; Appendix A). In early spring, temporary-pond Lestes larvae that are just hatched have a size disadvantage compared to larvae of L. eurinus that hatched the previous summer and which are already large at that moment (instar F-3 to F-1). We established an enclosure experiment to evaluate the role of predation by the large L. eurinus and Anax larvae in keeping the numbers of temporary-pond Lestes low in fishless permanent ponds and lakes.

Each of the experimental enclosures was stocked with temporary-pond Lestes. We studied their performance (final mass, survival) in a completely cross-factored design of the four combinations of the presence and absence of L. eurinus larvae and the Anax predator (Appendix B).

\section{Experiment 3: Laboratory predation experiment}

The outcome of this last enclosure experiment suggested that L. eurinus prey heavily upon small Lestes, but Anax do not. To test this explicitly, we also established a series of laboratory predation trials in which individual L. eurinus and Anax were allowed to feed on small Lestes. Trials were done in $20 \mathrm{~cm}$ diameter glass bowls covered with window screening to provide footing for the odonates (see McPeek 1990b). Bowls were filled with aged pond water to a depth of $5 \mathrm{~cm}$. To extrapolate our findings to fish-containing water bodies, we also ran trials with $L$. vigilax, and the typical aeshnid dragonfly predator, Basiaeshna janata, found in fish-containing habitats (see Appendix A). Ten small temporary-pond Lestes from Logging Pond were allowed to acclimate for $>2 \mathrm{~h}$ in a bowl before we randomly assigned each bowl to one of the following four treatments: no predator, one penultimate instar of Anax, Basiaeshna, or L. eurinus. We counted the surviving small Lestes after $24 \mathrm{~h}$. Six trials of each predator treatment were performed on 17 May.

Because the number of recovered larvae was zero in two of the trials, we calculated mortality rate as the proportion of larvae that died. Since no remains of larvae that were missing were found, we assume that all missing larvae were eaten.

\section{Experiment 4: Anax predation in a fishless permanent pond}

Lestes eurinus and L. vigilax are clearly restricted to the permanent part of the freshwater habitat gradient by their life history. In this experiment, we examined whether the strong affinity of L. vigilax for fish-containing permanent water bodies, and its absence from fishless permanent water bodies (Appendix A) was due to predation by large dragonfly larvae in the latter habitat type. Each of the experimental enclosures was stocked with larvae of both permanent-water Lestes. We studied their performance (survival, final size) under each of the two predator treatments: (1) no Anax predator added, and (2) one Anax predator added (Appendix B).

\section{Experiment 5: Fish predation in a fish-containing permanent lake}

In a second field experiment with permanent-lake Lestes, we tested whether the absence of L. eurinus in fish-containing permanent lakes (Appendix A) can be explained by exclusion via fish predation. Each of the experimental enclosures was stocked with both permanent-water Lestes. We studied their performance (survival, final size) under each of the two predator treatments: (1) no fish added, and (2) one fish added (Appendix B).

\section{Statistical analyses}

In experiments where we held two focal Lestes species within the same enclosure, not only the response variables (mortality rate, head size, and body mass) within one species, but also those between both species are potentially not independent. Ideally, when testing for an effect of predator, we should therefore perform a one-factor multivariate analysis of variance (MANOVA). However, the large number of response variables (six) relative to the level of replication (three or four) precluded this analytic approach. In such cases, we performed separate MANOVAs for the effect of the predator on the mortality rates of both species in one analysis, on head size of the two in a second analysis, and on body mass of the two in a third. If the MANOVA was significant we performed separate $t$ tests for each focal species. This approach is similar to the protected ANOVA approach described by Scheiner (1993).

Whenever one of our treatment variables had more than two levels, we tested for differences among these levels with Duncan a posteriori tests (Sokal and Rohlf 1995).

\section{RESUlts}

\section{Quantification of species occurrence along the gradient}

Total Lestes damselfly density did not differ among the four habitat types along the freshwater habitat gradient (ANOVA $F_{3,8}, P>0.54$; Appendix A). However, 
across the gradient there were dramatic shifts in individual species abundance, and these differences in species composition identify four Lestes assemblages in different habitat types: (1) L. dryas in vernal ponds (Duncan test, three pairwise comparisons with mean densities in other habitat types, all $P<0.026$ ); (2) $L$. congener (all $P<0.001$ ), L. disjunctus/forcipatus (all $P<0.036$ ), and $L$. rectangularis (all $P<0.005$ ) in temporary ponds; (3) L. eurinus in fishless permanent ponds (all $P<0.02$ ); and (4) L. vigilax in fish-containing permanent bodies of water (all $P<0.001$ ).

Anax dragonfly larvae and Acilius beetle larvae were the most abundant invertebrate predators in our samples. Both predator groups occupied different parts of the gradient. Anax larvae almost exclusively occurred in temporary ponds and fishless permanent bodies of water and their mean density did not differ between these habitat types (Duncan test $P>0.48$ ). The same pattern was found for newts (Notophthalmus viridescens). Acilius spp. larvae were the only abundant predator in vernal ponds; they are the only potential predator of L. dryas in these ponds, but our experience with them indicates that they are too small in size to impose significant mortality on Lestes populations. Dytiscus beetle larvae were more abundant in fishless permanent ponds than in the three other habitat types (Duncan tests, all pairwise comparisons $P<0.01$ ). Basiaeshna dragonfly larvae only occurred in fish-containing permanent bodies of water, although always at low densities (see also Johnson and Crowley 1980, McPeek 1990 a). Belostomatidae and Nepidae were very rare, and other taxa such as species in the Notonectidae and Naucoridae (Hemiptera) were present at low numbers.

Experiment 1: Anax predation experiment in a temporary pond

The MANOVA indicated a significant effect of Anax dragonflies on Lestes mortality rate $\left(F_{2,5}=15.53, P<\right.$ 0.01). L. dryas and the temporary-pond Lestes (i.e., $L$. disjunctus, L. forcipatus, and L. rectangularis) all had higher mortality rates in the presence of the Anax dragonfly than when Anax was absent $\left(t_{6}=6.01, P<0.001\right.$ and $t_{6}=2.73, P<0.05$; Fig. $1 \mathrm{~A}$ ), showing that dragonflies are a significant mortality source for these Lestes species when they co-occur. In the absence of Anax, L. dryas and the temporary-pond Lestes species had similar mortality rates (paired $t$ test, $t_{3}=2.37, P=$ 0.10 ). However, L. dryas had significantly higher mortality rates than the temporary-pond Lestes in the presence of Anax $\left(t_{3}=5.96, P<0.01\right)$.

The growth rates of all Lestes species were unaffected by the dragonfly predator treatments (MANOVAs for head width and body mass with $P>0.17$ ) (Fig. 1B-C).

Experiment 2: Anax and Lestes predation experiment in a fishless permanent pond

Mortality rates of small Lestes larvae were influenced by the interaction between L. eurinus and Anax (two-way ANOVA $F_{1,8}=10.74, P<0.02$; Fig. 1D). Across all treatments the presence of $L$. eurinus increased the mortality of small Lestes $\left(F_{1,8}=67.76, P\right.$ $<0.001)$. Surprisingly, mortality of small Lestes did not increase in the presence of an Anax dragonfly. In the absence of L. eurinus, the Anax larva imposed no detectible mortality on small Lestes $\left(F_{1,4}=1.58, P>\right.$ $0.25)$; in addition, the mortality of small Lestes in the presence of both Anax and L. eurinus was lower than in the presence of only L. eurinus $\left(F_{1,4}=9.54, P<\right.$ 0.04). This positive indirect effect of Anax on the survival of small Lestes was caused primarily through Anax reducing L. eurinus abundance. Indeed, in an ANCOVA with the number of recovered $L$. eurinus larvae as a covariate and the presence/absence of Anax as a main effect, the presence of Anax had no significant effect on small Lestes mortality $\left(F_{1,9}=0.54, P>0.45\right)$, but there was a positive relationship between the number of recovered L. eurinus larvae and the mortality of small Lestes $\left(R^{2}=0.93, F_{1,9}=126.16, P<0.001\right)$.

The final mass of the small Lestes was lower in the presence of L. eurinus $\left(F_{1,8}=48.00, P<0.001\right)$, but not affected by the presence of Anax $\left(F_{1,8}=0.62, P\right.$ $>0.45$; Fig. 1E). This reduction in body mass in the presence of $L$. eurinus could be due to a reduction of growth or positive size-biased predation. Only in the latter case is a reduction of the variance in body mass to be expected. The variance of body mass did not differ between treatments with and without $L$. eurinus (oneway ANOVA with the variation in body mass within an enclosure as dependent variable, $F_{1,9}=0.21, P>$ $0.65)$, which suggests that the reduction in mean body mass was the result of reduced growth of the small Lestes in the presence of the L. eurinus intraguild predator.

\section{Experiment 3: Laboratory predation experiment}

The outcome of the laboratory predation trials showed that small Lestes' mortality differed among treatments (log-transformed data, $F_{4,25}=68.11, P<$ $0.001)$. Duncan a posteriori tests showed two groups (all species differences between groups, $P<0.001$ ): (1) mortality was low and statistically not different when there was no predator $(0.08 \pm 0.03$; mean \pm 1 $\mathrm{SE})$, a Basiaeshna larva present $(0.13 \pm 0.02)$, or an Anax larva present $(0.25 \pm 0.04)$ and (2) high in the presence of $L$. eurinus $(0.85 \pm 0.04)$ or L. vigilax $(0.75$ $\pm 0.07)$. Hence, congeneric intraguild predation appears to be a major mortality source when Lestes larvae of one species are small, and large instars of another Lestes species are present.

\section{Experiment 4: Anax predation experiment in a fishless permanent pond}

Mortality rates of both native L. eurinus and transplanted L. vigilax were significantly increased by the presence of Anax dragonfly larvae. Anax significantly increased mortality rates of both transplanted L. vigilax 


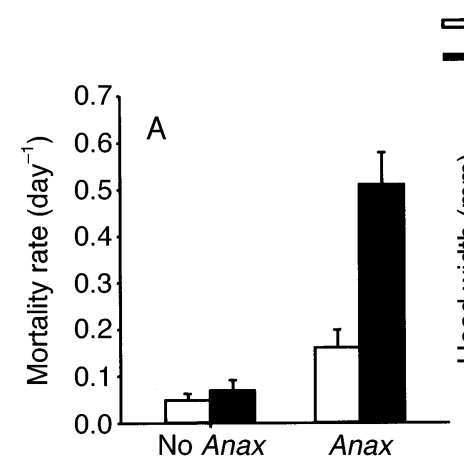

$\ulcorner$ Native temporary-pond Lestes

- Transplanted L. dryas
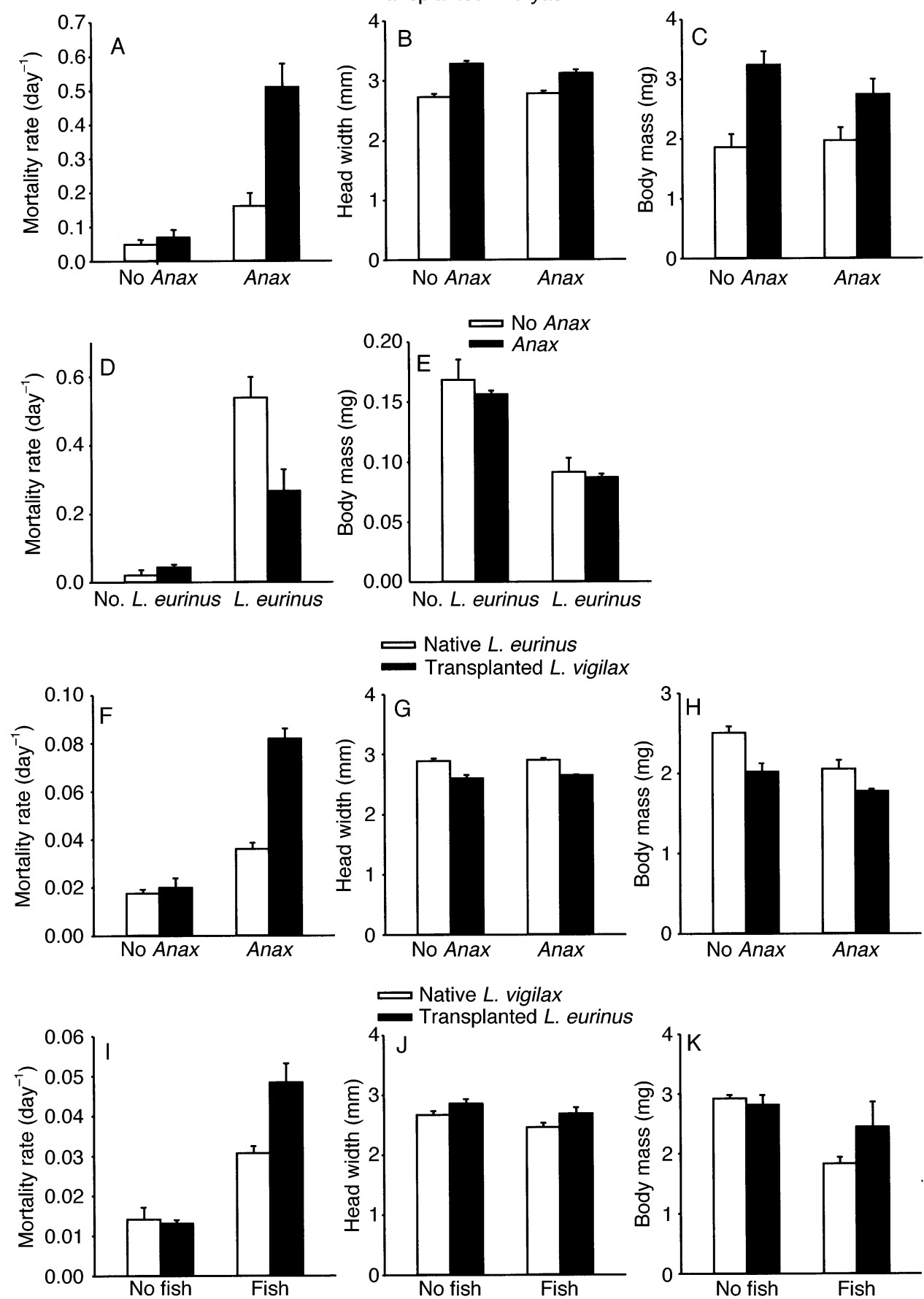

FIG. 1. Average mortality rates, final head widths, and body masses of native and transplanted Lestes collected at the end of the four enclosure experiments: (A-C) Experiment 1, Anax predation experiment in a temporary pond; (D-E) Experiment 2, Anax predation experiment in a fishless permanent pond; $(\mathrm{F}-\mathrm{H})$ Experiment 4, Anax predation experiment in a fishless permanent pond; and (I-K) Experiment 5, fish predation experiment in a fish-containing permanent water body. Error bars represent +1 SE. 
$\left(t_{4}=10.40, P<0.001\right)$ and native $L$. eurinus $\left(t_{4}=\right.$ 5.85, $P<0.01$; overall MANOVA, $F_{2,3}=64.78, P<$ 0.005 ; Fig. $1 \mathrm{~F}$ ) in the experiment done in the fishless permanent pond. In the absence of Anax, the mortality rates of the transplanted $L$. vigilax and the native $L$. eurinus were not different (paired $t$ test, $t_{2}=0.47, P$ $>0.45$ ), but the mortality rate of $L$. vigilax was much higher than that of L. eurinus in the presence of Anax $\left(t_{2}=6.80, P<0.03\right.$; Fig. $\left.1 \mathrm{~F}\right)$.

The presence of Anax did not reduce the final head width, but did reduce final body mass (MANOVA, $F_{2,3}$ $=0.74, P>0.55$ and $F_{2.3}=9.59, P=0.050$, respectively for head width and body mass; Fig. $1 \mathrm{G}-\mathrm{H}$ ). Body mass of L. eurinus was smaller in the presence of Anax than in their absence $\left(t_{4}=3.15, P<0.04\right)$, and mass of $L$. vigilax was marginally smaller in the presence of Anax $\left(t_{4}=2.33, P=0.08\right)$, suggesting that larvae of both species were growing slower in the presence of the Anax predator.

\section{Experiment 5: Fish predation in a fish-containing permanent lake}

The results of the MANOVA indicated that fish affected the mortality rate of the Lestes larvae $\left(F_{2,3}=\right.$ 19.90, $P<0.02)$. Both transplanted L. eurinus and native $L$. vigilax had higher mortality when fish were present than when fish were absent $\left(t_{4}=7.28, P<\right.$ 0.002 and $t_{4}=4.46, P<0.02$, for $L$. eurinus and $L$. vigilax, respectively; Fig. 1I). Again, both Lestes had comparable mortality rates in the absence of the predator (paired $t$ test, $t_{2}=0.42, P>0.70$ ), but the impact of fish on larval mortality was more severe on the transplanted $L$. eurinus than on the native $L$. vigilax $\left(t_{2}=\right.$ 5.99, $P<0.03)$.

The presence of fish had an overall effect on the sizes of recovered larvae of both species (MANOVA, $F_{2,3}=10.23, P<0.05$ and $F_{2,3}=30.12, P<0.01$, for head width and body mass, respectively). The presence of fish did not affect the head width of the recovered larvae for $L$. eurinus $\left(t_{4}=1.26, P>0.25\right)$ and only marginally reduced it for L. vigilax $\left(t_{4}=2.17, P<\right.$ 0.10; Fig. 1J). While the final body mass of $L$. eurinus was not affected by fish $\left(t_{4}=0.83, P>0.45\right)$, the final body mass of $L$. vigilax was considerably reduced in the presence of fish $\left(t_{4}=8.94, P<0.001\right.$; Fig. $\left.1 \mathrm{~K}\right)$. This suggests a growth reduction of $L$. vigilax larvae in the presence of fish.

\section{DISCUSSION}

\section{Habitat segregation and its underlying mechanisms}

Our quantitative survey results show a dramatic turnover in Lestes species along the freshwater habitat gradient. Each of the four types of freshwater habitats along the gradient imposes a specific set of constraints and is characterized by a single Lestes species or species group. This striking match between the four habitat types and Lestes species assemblages can be complete- ly explained by the interplay of species differences in life history and vulnerability to predation (Fig. 2). Most species ( $L$. congener, L. disjunctus, L. forcipatus, and $L$. rectangularis) were abundant in temporary ponds that also have large dragonfly populations. We also found small numbers of these species as small larvae at the time of sampling in lakes with fish and in one case in a vernal pond (Appendix A); our experience suggests that few if any of these larvae in fish lakes or vernal ponds will survive to adulthood, and so these small populations probably represent sinks (Pulliam 1988) for these species. The three other Lestes species were almost exclusively found in a particular but different part of the gradient: L. dryas dominated vernal ponds, $L$. eurinus dominated fishless permanent ponds and lakes, and L. vigilax dominated fish-containing permanent ponds and lakes (Appendix A). This pattern is in agreement with a broader, qualitative survey of 27 sites we conducted across the gradient in Vermont and New Hampshire for the presence or absence of larvae and newly emerged adults (R. Stoks and M. A. McPeek, personal observation), and with other studies on the distribution of Lestes damselflies across North America: L. dryas is known as a typical species of vernal ponds (Walker 1953, Sawchyn and Gillott 1974, Wiggins et al. 1980, Cannings and Cannings 1987), L. disjunctus and $L$. congener occur in temporary ponds that do not dry until mid-August (Cannings and Cannings 1987), L. eurinus is a specialist of fishless permanent water bodies (Johnson and Crowley 1980, Crowley and Johnson 1982), and L. vigilax is a specialist of fishcontaining permanent water bodies (Johnson and Crowley 1980, Crowley and Johnson 1992).

Role of life history in shaping Lestes assemblages.Life history played a key role in shaping species turnover along the gradient in two ways: (1) by determining the ability of species to cope with drying regime and (2) by mediating species exclusion through intraguild predation. Not unexpectedly, the only Lestes specialized in vernal ponds, L. dryas, has a higher growth rate than Lestes from the other habitat types (R. Stoks and M. A. McPeek, unpublished data) and emerges earlier in the summer before other Lestes (Sawchyn and Gillott 1974). Temporary-pond Lestes, such as L. congener and $L$. disjunctus, probably cannot develop fast enough at the relative lower temperatures associated with vernal ponds, and as a result, are eliminated in the larval stage by early pond drying (see also Jödicke 1997). At the other end of the gradient, permanent-water Lestes are largely excluded from temporary ponds because their eggs hatch immediately in late summer (Lutz 1968, Paulson and Jenner 1971): therefore, they cannot bridge the dry period in the egg stage as the temporarypond Lestes do (Jödicke 1997).

Life history also shaped species distributions along the gradient by inducing asymmetric interactions between temporary-pond and permanent-water Lestes. The near absence of temporary-pond Lestes in fishless 


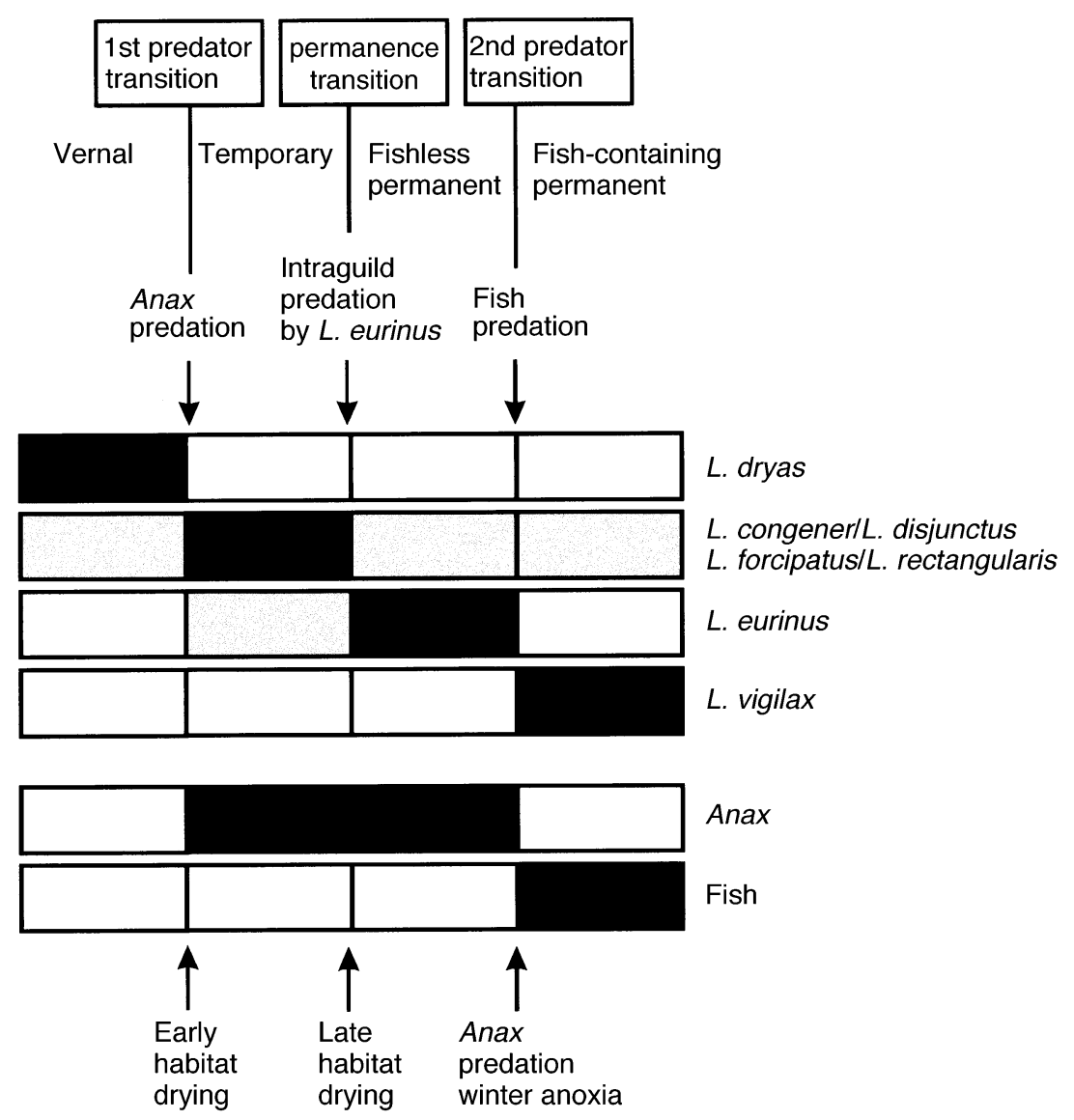

FIG. 2. Schematic overview of the four habitat types and three transitions along the freshwater habitat gradient. The ranges of Lestes species are represented by coded bars (black $=$ abundant, gray $=$ rare, white $=$ absent) in relation to pond drying and predation. Arrows indicate ecological forces that limit a species' range along the gradient. Arrows above the species bars represent processes that restrict a species to the less permanent side of the gradient, and arrows below represent processes that restrict a species to the more permanent side of the gradient. Anax predation limits the range of $L$. vigilax, and winter anoxia limits the range of fish to fish-containing permanent water bodies.

permanent water bodies cannot be due to predation by dragonflies. Indeed, large dragonfly larvae are the top predators in both temporary ponds and fishless permanent ponds, and their densities did not differ between the two habitat types (Appendix A, Fig. 2). Temporary-pond Lestes were instead excluded from fishless permanent bodies of water through asymmetric intraguild predation by L. eurinus (Experiments 2 and 3 ). Because of their direct development, L. eurinus larvae are already in late instars when the larvae of temporarypond Lestes hatch in the spring. The size advantage linked with this life history-induced priority effect makes it possible for L. eurinus to exert very high mortality rates on temporary-pond Lestes. At natural densities, L. eurinus larvae could eliminate almost all small temporary-pond Lestes in the bucket enclosure experiment after five days (Experiment 2). The surviving temporary-pond Lestes larvae also had a reduced growth in the presence of $L$. eurinus larvae. This would probably be due to interference effects, since small Lestes and L. eurinus would be feeding on very different prey because of their size differences (see, e.g., Havel et al. 1993), and would thus probably not compete directly for resources. Predation by large $L$. eurinus larvae and dragonfly predation would also exclude small L. dryas from fishless permanent water bodies.

Additional evidence that $L$. eurinus precludes temporary-pond Lestes from invading fishless permanent habitats comes from biogeography. L. eurinus only occurs in northeastern North America, while the temporary-pond Lestes, L. congener, and L. disjunctus are widespread across the entire continent (Westfall and May 1996). This creates a natural experiment to see whether L. eurinus restricts these species to temporary ponds. In accordance with our experimental results, $L$. disjunctus is able to establish large populations in fishless permanent ponds where it occurs in allopatry with L. eurinus (in Alberta [Krishnaraj and Pritchard 1995], Colorado [Wissinger et al. 1999a], Montana [Eriksen 1984], and Texas [Abbott 2001]). A similar niche expansion of temporary-pond Lestes is seen in Europe, 
where permanent-water Lestes are absent. In contrast with the pattern observed in northeastern North America, most European Lestes species are dominant in temporary ponds, but also occur in large numbers in fishless permanent water bodies (Jödicke 1997; R. Stoks, personal observation).

Role of large dragonfly and fish predation in shaping Lestes assemblages.-Predation pressure differed both in a quantitative and in a qualitative way along the gradient. Due to their short hydroperiod, vernal ponds lack the large invertebrate top predators (mainly large Anax dragonfly larvae) that dominate temporary ponds and fishless permanent water bodies (Appendix A; see, e.g., Smith 1983). Our survey further showed that fishless systems were characterized by the presence of the larger and more active A. junius, while in fish-containing systems, the smaller, less active $B$. janata dominates, and many other smaller anisopteran species are also present in lower abundances (see also McPeek 1990a, Werner and McPeek 1994). Large dragonfly predators like Anax are excluded from fish-containing water bodies by fish predation (Crowder and Cooper 1982, Morin 1984, Werner and McPeek 1994). Fish typically are excluded from the less permanent water bodies by oxygen stress and pond drying (e.g., Tonn and Magnuson 1982, Rahel 1984), and many ponds are fishless because no routes of colonization (e.g., connecting streams) are available for fish.

Our enclosure experiments showed that these changing predator assemblages (the presence or absence of large dragonfly larvae and fish in particular) along the gradient explained several Lestes species distribution boundaries (Fig. 2). One, L. dryas, seems unable to coexist with either of these two key predators and adopted a fugitive strategy (sensu Sih 1987) by only occurring in vernal ponds (Experiment 1). This is further supported by the fact that the only temporary pond in our larger survey where L. dryas was present (even in high numbers), at the Ray Elementary School of Hanover (New Hampshire), was one where large aeshnid dragonfly larvae were absent (R. Stoks and M. A. McPeek, unpublished data).

The two permanent-water Lestes differed strongly in their vulnerability to each of these two key predators: L. eurinus was less vulnerable than $L$. vigilax to Anax predation, while L. vigilax was less vulnerable than $L$. eurinus to fish predation (Experiments 4 and 5). This pattern of reciprocal dominance of prey species under different predation regimes is a widespread phenomenon within other vertebrate and invertebrate genera. As repeatedly shown in other systems that differ in the background predator community, allopatric predators impose greater mortality, and this is clearly a force limiting part of the present species distribution (Woodward 1983, Pierce et al. 1985, McPeek 1990a, $b$; Wissinger et al. 1999b, Relyea 2001). The same behavioral mechanisms as found in Enallagma damselflies seem to underlie the habitat segregation between both per- manent-water Lestes (R. Stoks and M. A. McPeek, unpublished data). The fact that both permanent-water Lestes lower their foraging effort in the presence of Anax, but only L. vigilax does so in the presence of fish, makes them differentially vulnerable to both predators and may also explain why both species have a reduced growth rate in the presence of Anax, but that only $L$. vigilax suffered a reduced growth rate in the presence of fish (Experiments 4 and 5).

Besides direct effects, we have indications that also indirect effects (sensu Wootton 1994) of Anax dragonfly predation may be at work along the gradient (Experiment 2). The presence of large dragonfly larvae had a positive indirect effect on the survival of small temporary-pond Lestes transmitted through its effects on L. eurinus. Such indirect effects can be due to changes in the abundance or changes in the per capita effect of the intermediate transmitting species (Morin 1999). Our results suggest that the indirect effect we observed was mediated by a reduction in L. eurinus abundance due to Anax predation. At our study sites, this positive indirect effect appeared to be too small to allow the coexistence of temporary-pond Lestes and L. eurinus. At sites with a higher Anax predation and/or lower $L$. eurinus densities, Anax may, however, act as a keystone predator (sensu Mills et al. 1993) by preferentially consuming the L. eurinus that would otherwise eliminate temporary-pond Lestes. This mechanism may be at work in those temporary ponds that do not dry in a given year. At present this is only conjecture and additional experimental work is needed to evaluate the potential context-dependent keystone role of large dragonfly larvae (see also Fauth 1999).

\section{Community types and transitions along the gradient}

Our results are largely consistent with the mechanisms shaping community structure along the gradient of freshwater bodies as reviewed by Wellborn et al. (1996). Along the gradient, they recognized three community types separated by two important transitions: (1) the permanence transition that separates non-permanent and permanent habitats and (2) the predator transition that separates permanent water bodies dominated by invertebrate top predators and permanent water bodies dominated by fish. However, an important difference with our findings is that they assume that the permanence transition also coincides with the shift from communities without predators to communities with large invertebrate top predators. For ponds in our area of North America, the invertebrate predation and hydroperiod transitions are not coincident; densities of large dragonfly predators do not differ between temporary ponds and fishless permanent water bodies (Appendix A, Fig. 2; see also Snodgrass et al. 2000). Instead, the transition towards communities dominated by invertebrate top predators occurs when going from vernal ponds to temporary ponds; what we would call the first predator transition (as opposed to the second 
one separating permanent waters with invertebrate top predators and permanent waters with fish). We believe this mismatch between the first predator transition and the permanence transition to be general. Indeed, other studies have shown that large dragonfly predators can be abundant and important top predators in non-permanent ponds (e.g., Skelly 1996, Wilbur 1997, Williams 1997, Fauth 1999, Higgins and Merritt 1999; see also Richardson 2001). Because species of several taxa can be eliminated by predation by large dragonfly larvae in temporary ponds (e.g., anurans [Woodward 1983, Fauth 1999], odonates [see Results], diptera [Stav et al. 2000]), community structure differs largely at both sides of this first predator transition, justifying the discrimination between vernal ponds and temporary ponds. The presence of invertebrate top predators on both sides of the permanence transition does not invalidate this transition; it should be kept, but for other reasons.

Species assemblages may differ at both sides of the permanence transition due to strong asymmetric interactions by congeneric species (not necessarily top predators, as in our study system), which are restricted to permanent ponds. The same life history constraint that keeps these permanent fishless pond species from living in temporary ponds should give them a size advantage against congeneric species living in temporary ponds. Taken together, this justifies the view of four community types separated by three transitions along the freshwater habitat gradient (Fig. 2; see also Snodgrass et al. 2000).

\section{Maintaining and generating biodiversity along the gradient}

Our results showed that pond drying and predation interact in structuring Lestes assemblages and maintaining biodiversity along the gradient. On a local scale, these selective forces sharply reduce Lestes species richness; one single habitat-specific Lestes species dominates vernal ponds and fishless and fish-containing permanent water bodies. Different selective forces, however, create refuge habitats for species that cannot coexist with a certain predator. For example, L. dryas and $L$. vigilax are both unable to live in temporary ponds and fishless permanent waters because of the presence of large Anax larvae; pond drying allows $L$. dryas to persist in vernal ponds, and fish predation allows L. vigilax to persist in fish-containing permanent water bodies. As a result, the availability of alternative habitat types along the gradient allows more Lestes species to coexist on a regional scale. In other words, the strong habitat-specific selection regimes along the gradient decrease local species richness, while at the same time increasing regional species richness.

The same ecological forces that today maintain habitat segregation and thereby the regional species pool also may have been the selective forces that generated the regional species pool. Indeed, adaptation to local ecological conditions may play a significant role in generating new species and shaping local community structure (Wellborn et al. 1996, McPeek and Brown 2000, Schluter 2000). In agreement with the fact that habitat-specific selection pressures are often severe and incompatible, habitat specialization as seen in the genus Lestes is pronounced along the gradient (Wellborn et al. 1996). This suggests that the common ancestor of the extant Lestes species may also have had a limited distribution along the gradient and that speciation may have been linked with habitat shifts. For the moment we are exploring this scenario within the genus Lestes by reconstructing their phylogeny. Preliminary data suggest that temporary ponds are the ancestral habitat for Lestes damselflies (M. A. McPeek and R. Stoks, unpublished data). Successful habitat shifts toward vernal ponds and permanent water bodies would have given rise to new species, thereby increasing regional species richness (e.g., McPeek and Brown 2000). Clearly, to fully exploit the freshwater habitat gradient as a potential template for the evolutionary assembly of communities, studies of diversification of the multitude of taxa that segregate along the entire gradient should be coupled with experimental tests of mechanisms promoting local and regional coexistence of these lineages. Because of the relative ease in identifying key evolutionary and ecological processes in this system, we think that the study of assemblages of closely related species along an environmental gradient may be the ideal system in which to explore how an entire ecosystem may have been assembled over evolutionary time (see also Wellborn et al. 1996, McPeek and Brown 2000, Richardson 2001).

\section{ACKNOWLEDGMENTS}

We would like to thank the following people for their very appreciated help in several stages of the enclosure experiment in McDaniels Marsh: Stephen "Chip', Glaholt, Jr., for placing the enclosures; Nick Friedenburg, Ryan Thum, Julie Turgeon, and Ian White for picking the Lestes larvae; and Curtis McPeek for doing a great job in catching the pumkinseeds. Sofie De Pooter is gratefully acknowledged for her assistance with the enclosure experiment in Sylvester Pond. The owners of Hemphill Pond, Johnson Pond, Montshire Museum Pond, and Sylvester Pond generously allowed our presence on their properties. Jens Rolff and Frank Johansson gave valuable comments on this manuscript. R. Stoks is a postdoctoral fellow of the Fund for Scientific Research Flanders (FWO-Flanders). The work was supported by grants from FWO-Flanders to R. Stoks and by grants from the National Science Foundation (USA) to M. A. McPeek.

\section{Literature Cited}

Abbott, J. C. 2001. Distribution of dragonflies and damselflies (Odonata) in Texas. Transactions of the American Entomological Society 127:199-228.

Arnott, S. E., and M. J. Vanni. 1993. Zooplankton assemblages in fishless bog lakes: influence of biotic and abiotic factors. Ecology 74:2361-2380.

Batzer, D. P., and S. A. Wissinger. 1996. Ecology of insect communities in nontidal wetlands. Annual Review of Entomology 41:75-100. 
Bendell, B. E. 1986. The effects of fish and pH on the distribution and abundance of backswimmers (Hemiptera, Notonectidae). Canadian Journal of Zoology 64:2696-2699.

Bendell, B. E., and D. K. McNicol. 1987. Fish predation, lake acidity and the composition of aquatic insect assemblages. Hydrobiologia 150:193-202.

Bilton, D. T., A. Foggo, and S. D. Rundle. 2001. Size, permanence and the proportion of predators in ponds. Archiv für Hydrobiologie 151:451-458.

Brooks, J. L., and S. I. Dodson. 1965. Predation, body size and the composition of the plankton. Science 150:28-35.

Cannings, R. A., and S. G. Cannings. 1987. The Odonata of some saline lakes in British Columbia: ecological distribution and zoogeography. Advances in Odonatology 3:721.

Crowder, L. B., and W. E. Cooper. 1982. Habitat structural complexity and the interaction between bluegills and their prey. Ecology 63:1802-1813.

Crowley, P. H., and D. M. Johnson. 1982. Habitat and seasonality as niche axes in an odonate community. Ecology 63:1064-1077.

Crowley, P. H., and D. M. Johnson. 1992. Variability and stability of a dragonfly assemblage. Oecologia 90:260-269.

Dodson, S. I. 1974. Zooplankton competition and predation: an experimental test of the size-efficiency hypothesis. Ecology 55:121-127.

Eriksen, C. H. 1984. The physiological ecology of larval Lestes disjunctus Selys (Zygoptera: Odonata). Freshwater Invertebrate Biology 3:105-117.

Fauth, J. E. 1999. Identifying potential keystone species from field data: an example from temporary ponds. Ecology Letters 2:36-43.

Gower, J. L., and E. J. Kormondy. 1963. Life history of the damselfly Lestes rectangularis with special reference to seasonal regulation. Ecology 44:398-402.

Havel, J. E., J. Link, and J. Niedzwiecki. 1993. Selective predation by Lestes (Odonata, Lestidae) on littoral microcrustacea. Freshwater Biology 29:47-58.

Higgins, M. J., and R. W. Merritt. 1999. Temporary woodland ponds in Michigan: invertebrate seasonal patterns and trophic relationships. Pages 279-297 in D. P. Batzer, R. B. Rader, and S. A. Wissinger, editors. Freshwater wetlands of North America: ecology and management. John Wiley and Sons, New York, New York, USA.

Jeffries, M. 1994. Invertebrate communities and turnover in wetland ponds affected by drought. Freshwater Biology 32: 603-612.

Jödicke, R. 1997. Die Binsenjungfern und Winterlibellen Europas. Westarp, Heidelberg, Germany.

Johnson, D. M., and P. H. Crowley. 1980. Habitat and seasonal segregation among coexisting odonate larvae. Odonatologica 9:297-308.

Kats, L. B., J. W. Petranka, and A. Sih. 1988. Antipredator defenses and the persistence of amphibian larvae with fishes. Ecology 69:1865-1870.

Knapp, R. A., K. R. Matthews, and O. Sarnelle. 2001. Resistance and resilience of alpine lake fauna to fish introductions. Ecological Monographs 71:401-421.

Krishnaraj, R., and G. Pritchard. 1995. The influence of larval size, temperature, and components of the functional response to prey density on growth rates of the dragonflies Lestes disjunctus and Coenagrion resolutum (Insecta: Odonata). Canadian Journal of Zoology 73:1672-1680.

Lutz, P. E. 1968. Life-history studies on Lestes eurinus Say (Odonata). Ecology 49:576-579.

McNicol, D. K., B. E. Bendell, and R. K. Ross. 1987. Studies of the effects of acidification on aquatic wildlife in Canada: waterfowl and trophic interactions in small lakes in northern Ontario. Canadian Wildlife Service Occasional Paper Number 62, Ottawa, Canada.
McPeek, M. A. 1990a. Determination of species composition in the Enallagma damselfly assemblages of permanent lakes. Ecology 71:83-98.

McPeek, M. A. 1990b. Behavioral differences between Enallagma species (Odonata) influencing differential vulnerability to predators. Ecology 71:1714-1726.

McPeek, M. A. 1998. The consequences of changing the top predator in a food web: a comparative experimental approach. Ecological Monographs 68:1-23.

McPeek, M. A., and J. M. Brown. 2000. Building a regional species pool: diversification of the Enallagma damselflies in eastern North America. Ecology 81:904-920.

Mills, L. S., M. E. Soulé, and D. F. Doak. 1993. The keystone concept in ecology and conservation. BioScience 43:219224.

Morin, P. J. 1984. Odonate guild composition: experiments with colonization history and fish predation. Ecology 65: $1866-1873$

Morin, P. J. 1999. Community ecology. Blackwell Science, Boston, Massachusetts, USA.

Optimas. 1996. Optimas, version 6.1. Optimas Corporation, Bothell, Washington, USA.

Paulson, D. R., and C. E. Jenner. 1971. Population structure in overwintering larval Odonata in North Carolina in relation to adult flight season. Ecology 52:96-107.

Pierce, C. L., P. H. Crowley, and D. M. Johnson. 1985. Behavior and ecological interactions of larval Odonata. Ecology 66:1504-1512.

Pulliam, H. R. 1988. Sources, sinks, and population regulation. American Naturalist 132:652-661.

Rahel, F. J. 1984. Factors structuring fish assemblages along a bog lake successional gradient. Ecology 65:1276-1289.

Relyea, R. A. 2001. The relationship between predation risk and antipredator responses in larval anurans. Ecology 82: 541-554.

Richardson, J. M. L. 2001. The relative roles of adaptation and phylogeny in determination of larval traits in diversifying anuran lineages. American Naturalist 157:282-299.

Sawchyn, W. W., and C. Gillott. 1974. The life history of three species of Lestes (Odonata: Zygoptera) in Saskatchewan. Canadian Entomologist 106:1283-1293.

Scheiner, S. M. 1993. MANOVA: multiple response variables and multiple species interactions. Pages 95-112 in S. M. Scheiner and J. Gurevitch, editors. Design and analysis of ecological experiments. Chapman and Hall, New York, New York, USA

Schluter, D. 2000. The ecology of adaptive radiation. Oxford Series in Ecology and Evolution, Oxford University Press, Oxford, UK.

Schneider, D. W. 1997. Predation and food web structure along a habitat duration gradient. Oecologia 110:567-575.

Sih, A. 1987. Predators and prey lifestyles: an evolutionary and ecological overview. Pages 203-224 in W. C. Kerfoot and A. Sih, editors. Predation: direct and indirect impacts on aquatic communities. University Press of New England, Hanover, New Hampshire, USA.

Skelly, D. K. 1995. A behavioral trade-off and its consequences for the distribution of Pseudacris treefrog tadpoles. Ecology 76:150-164.

Skelly, D. K. 1996. Pond drying, predators, and the distribution of Pseudacris tadpoles. Copeia 1996:599-605.

Smith, D. C. 1983. Factors controlling tadpole populations of the chorus frog (Pseudacris triseriata) on Isle Royal, Michigan. Ecology 64:501-510.

Smith, D. C., and J. Van Buskirk. 1995. Phenotypic design, plasticity, and ecological performance in two tadpole species. American Naturalist 145:211-233.

Snodgrass, J. W., A. L. Bryan, and J. Burger. 2000. Development of expectations of larval amphibian assemblage 
structure in southeastern depression wetlands. Ecological Applications 10:1219-1229.

Sokal, R. R., and F. J. Rohlf. 1995. Biometry. Third edition. W. H. Freeman, New York, New York, USA.

Sprules, W. G. 1972. Effects of size-selective predation and food competition on high-altitude zooplankton communities. Ecology 53:375-386.

Stav, G., L. Blaustein, and Y. Margalit. 2000. Influence of nymphal Anax imperator (Odonata: Aeshnidae) on oviposition by the mosquito Culiseta longiareolata (Diptera: $\mathrm{Cu}$ licidae) and community structure in temporary pools. Journal of Vector Ecology 25:190-202.

Tonn, W. M., and J. J. Magnuson. 1982. Patterns in the species composition and richness of fish assemblages in northern Wisconsin lakes. Ecology 63:1149-1166.

Walker, E. M. 1953. The Odonata of Canada and Alaska. University of Toronto Press, Toronto, Canada.

Wellborn, G. A. 1995. Predator community composition and patterns of variation in life-history and morphology among Hyalella (amphipoda) populations in southeast Michigan. American Midland Naturalist 133:322-332.

Wellborn, G. A. 2002. Trade-off between competitive ability and antipredator adaptation in a freshwater amphipod species complex. Ecology 83:129-136.

Wellborn, G. A., D. K. Skelly, and E. E. Werner. 1996. Mechanisms creating community structure across a freshwater habitat gradient. Annual Review of Ecology and Systematics 27:337-363.

Werner, E. E., and B. R. Anholt. 1996. Predator-induced behavioral indirect effects: consequences to competitive interactions in anuran larvae. Ecology 77:157-169.

Werner, E. E., and M. A. McPeek. 1994. Direct and indirect effects of predators on two anuran species along an environmental gradient. Ecology 75:1368-1382.
Westfall, M. J., Jr., and M. L. May. 1996. Damselflies of North America. Scientific Publishers, Gainesville, Florida, USA.

Wiggins, G. B., R. J. Mackay, and I. M. Smith. 1980. Evolutionary and ecological strategies of animals in annual temporary pools. Archiv für Hydrobiologie 58:97-206.

Wilbur, H. M. 1997. Experimental ecology of food webs: complex systems in temporary ponds. Ecology 78:22792302.

Williams, D. D. 1996. Environmental constraints in temporary fresh waters and their consequences for the insect fauna. Journal of the North American Benthological Society 15:634-650.

Williams, D. D. 1997. Temporary ponds and their invertebrate communities. Aquatic conservation: marine and freshwater ecosystems. 7:105-117.

Wissinger, S. A., J. Bohonak, H. W. Whiteman, and W. S. Brown. 1999a. Subalpine wetlands in Colorado: habitat permanence, salamander predation, and invertebrate communities. Pages 757-790 in D. P. Batzer, R. B. Rader, and S. A. Wissinger, editors. Freshwater wetlands of North America: ecology and management. John Wiley and Sons, New York, New York, USA.

Wissinger, S. A., H. H. Whiteman, G. B. Sparks, G. L. Rouse, and W. S. Brown. 1999b. Foraging trade-offs along a predator-permanence gradient in subalpine wetlands. Ecology 80:2102-2116.

Woodward, B. D. 1983. Predator-prey interactions and breeding-pond use of temporary-pond species in a desert anuran community. Ecology 64:1549-1555.

Wootton, J. T. 1994. The nature and consequences of indirect effects in ecological communities. Annual Review of Ecology and Systematics 25:443-446.

\section{APPENDIX A}

Sampling methods and a table of quantitative density estimates of Lestes damselfly larvae and predators are available in ESA's Electronic Data Archive: Ecological Archives E084-040-A1.

\section{APPENDIX B}

A description of the setup of the enclosure experiments is available in ESA's Electronic Data Archive: Ecological Archives E084-040-A2. 